\title{
Use of Landsat thermal imagery for dynamically monitoring spontaneous combustion of Datong Jurassic coalfields in China
}

\author{
Yongan Xue ${ }^{1, *}$, Jin $\mathrm{LiU}^{2}$, Jun $\mathrm{Li}^{2}$, Changsheng Shang ${ }^{2}$, Jinling ZhaO ${ }^{3}$ \\ and Mingmei ZHANG ${ }^{1,4}$ \\ ${ }^{1}$ College of Mining Engineering, Taiyuan University of Technology, Taiyuan 030 024, China. \\ ${ }^{2}$ Geological Environmental Center of Shanxi Province, Taiyuan 030 024, China. \\ ${ }^{3}$ Anhui Engineering Laboratory of Agro-Ecological Big Data, Anhui University, Hefei 230 601, China. \\ ${ }^{4}$ Department of Geology and Surveying and Mapping, Shanxi Energy Institute, Taiyuan 030 600, China. \\ *Corresponding author. e-mail: anantyut@163.com
}

MS received 16 February 2017; revised 27 July 2017; accepted 29 September 2017; published online 22 May 2018

It is highly helpful and necessary to investigate and monitor the status of coal seam. Fortunately, remote sensing has facilitated the identification and dynamical monitoring of spontaneous combustion for a large area coal mining area, especially using the time series remotely-sensed datasets. In this paper, Datong Jurassic coal mining area is used as the study area, China, and an exclusion method and a multiplefactor analysis method are jointly used to identify the spontaneous combustion, including land surface temperature (LST), burnt rocks, and land use and land cover change (LUCC). The LST is firstly retrieved using a single-window algorithm due to a thermal infrared band of Landsat-5 TM (Thematic Mapper). Burnt rocks is then extracted using a decision-tree classification method based on a high-resolution SPOT-5 image. The thermal anomaly areas are identified and refined by the spatial overlay analysis of the above affecting factors. Three-period maps of coal fire areas are obtained and dynamically analyzed in 2007, 2009 and 2010. The results show that a total of 12 coal fire areas have been identified, which account for more than $1 \%$ of the total area of the study area. In general, there is an increasing trend yearly and a total of $771,970 \mathrm{~m}^{2}$ is increased. The average annual increase is $257,320 \mathrm{~m}^{2}$, the average annual growth rate is $3.78 \%$, and the dynamic degree is $11.29 \%$.

Keywords. Remote sensing; Datong Jurassic coalfield; Landsat TM; spontaneous combustion; land surface temperature.

\section{Introduction}

Coal spontaneous combustion, especially for the underground coal seam, is generally caused due to the natural or human factors. A serious coal fire can be formed along with the gradual spread of spontaneous combustion over time in the ground (Hu et al. 2015; Ren et al. 2015). Underground coal spontaneous combustion has a long history in China, and has a wide spatial distribution, especially in the northern regions ( $\mathrm{Lu}$ and Qin 2015). More and more attention has been paid to the detection and monitoring of underground coal fires. Currently, geophysical exploration methods are mainly used for detecting coal-seam spontaneous combustion, including the magnetic detection, 
electrical detection and radon measurement techniques (Stracher and Taylor 2004; Nelson and Chen 2007; Xue et al. 2008). The geophysical techniques are aimed at detecting the changes of magnetism, resistivity, radioactivity, etc., of surrounding rocks when spontaneous combustion of coal seam occurs. They are usually used to obtain the thermal anomaly for a certain sample point. It is impossible to learn about the coal spontaneous combustion for the whole coalfield. Recently, the emergence of remote sensing technology has facilitated the identification and dynamic monitoring of spontaneous combustion, due to the fast identification, dynamic monitoring and quantitative assessment (Rosema et al. 2001). More importantly, remote sensing imagery can cover a large-scale region and be used for acquiring spontaneous combustion for a large-scale mining area. The remote sensing based method can make up the deficiency of traditional point-based geophysical exploration methods.

At present, identification of geothermal resources is usually achieved based on the geological tectonic analysis and the remote sensing based interpretation (Hochstein and Dickinson 1970; Oppenheimer 1986). Wang et al. (2016) established a foundation for prevention and control of spontaneous combustion using simultaneous thermal analysisFourier transform infrared spectroscopy. Pal et al. (2016) dealt with the coal fire mapping of using the magnetic method which is based on the fact that rise in temperature would result significant changes in magnetic susceptibility and thermoremanent magnetization (TRM) of the overlying rocks. Hu and Xia (2017) developed a new methodology for monitoring spontaneous combustion of coal waste dumps based on a 3D temperature distribution model. Most of the results are qualitative and larger errors have been observed. For instance, the thermal infrared (TR) bands of coarse resolution remote sensing imagery (e.g., NOAA/AVHRR, MODIS) have been generally used to obtain land surface temperature (LST) and investigate geothermal resources by a splitwindow algorithm. Singh et al. (2017) evaluated and mapped coal fire by deriving LST of the anomalous areas based on ASTER (Advanced Spaceborne Thermal Emission and Reflection) data. Unfortunately, more thermal anomalies cannot be found, especially for the thermal spatial distribution, due to the $1 \mathrm{~km}$ coarse resolution. In contrast, there is only a TR band for Landsat Thematic Mapper (TM) and Enhanced Thematic
Mapper Plus (ETM+) series, but the spatial resolution can reach $30 \mathrm{~m}$ and higher resolution LST can be derived for retrieving geothermal related resources more accurately. Jiang et al. (2017) used spatiotemporal Landsat TM and ETM+ images to detect changes in coal fires by utilizing a generalized single-channel method.

Spontaneous combustion of underground coal seam is very serious in Datong Jurassic coal mining area, Shanxi Province, China. At present, most studies are focused on the identification of coal fire areas in a certain region using thermal infrared remote sensing data, including Jurassic coal mining area and Majiliang mine coal fire. It is highly necessary and important to investigate the distribution and development trend of the whole coal mining area. More ancillary data must be used to develop an integrated methodology for acquiring the accurate spontaneous combustion of coal seam. Consequently, in this study, Datong Jurassic coalfield is chosen as the study area, and three period Landsat-5 TM thermal infrared images of 2007, 2009 and 2010 are taken as the data sources. The land surface temperature (LST) is retrieved by the single-window algorithm and the burning rocks are identified by a decision-tree classification method using a SPOT-5 image. Eventually, an exclusion method and a multiple-factor analysis method including LST, burnt rocks, roads, land use and land cover change (LUCC), are jointly used to identify distribution of coal fire areas by the spatial overlay analysis.

\section{Materials and methods}

\subsection{Study area}

The Datong Jurassic coal field is located in the southwest of Datong, northern Shanxi Province, China, with three parts of Jurassic coal seams area including Nanjiao, Xinrong District and Zuoyun County (figure 1). Flat loess hilly tablelands are the primary geomorphological types in the study area, with the higher relief amplitude in the southwest and lower in the northeast. The elevation of Yujing area is $1500 \mathrm{~m}$, while it is $1200 \mathrm{~m}$ of Yungang area, with an elevation of $1200-1400 \mathrm{~m}$. The total area of Datong Jurassic coal field is $632 \mathrm{~km}^{2}$, and the coal mine production has reached 87 million tons annually. According to the available information, coal-seam spontaneous combustion disasters in the region is extremely serious, especially in Fengzijian, 


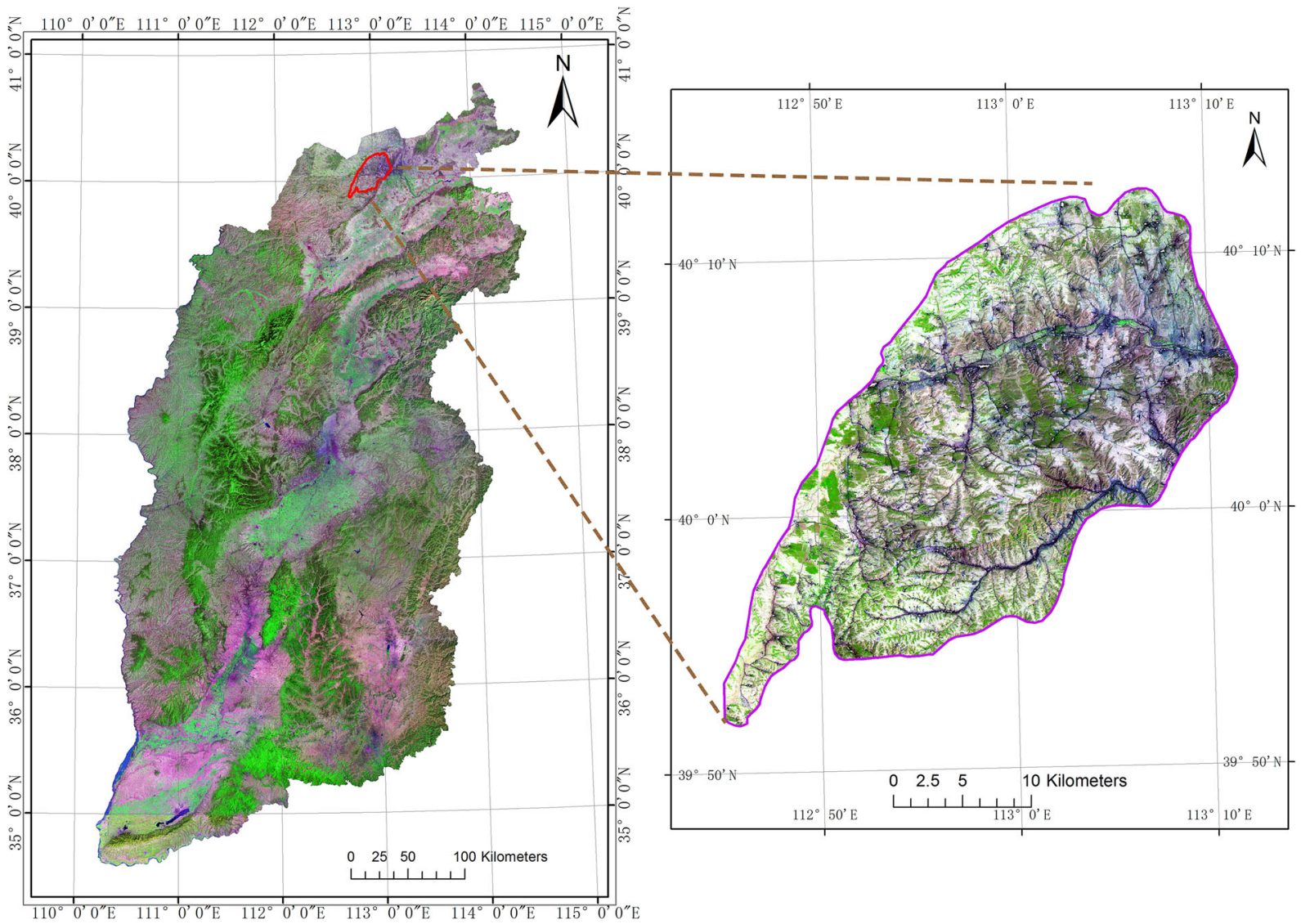

Figure 1. Geographic location of the study area.

Table 1. Time series data sources for monitoring coal spontaneous combustion.

Remote sensing dataset

\begin{tabular}{|c|c|c|c|}
\hline Acquisition time & Multi-spectral bands & Thermal-infrared band & Ancillary data \\
\hline 2007.09.15 & Landsat-5 TM bands $1-5,7$ & Band 6 & $\begin{array}{l}\text { (1) } 1: 50000 \text { topographic } \\
\text { map with total elements }\end{array}$ \\
\hline 2009.09.20 & Landsat-5 TM bands $1-5,7$ & Band 6 & $\begin{array}{l}\text { (2) Spatial distribution } \\
\text { map of mining areas }\end{array}$ \\
\hline 2010.07 .05 & Landsat-5 TM bands $1-5,7$ & Band 6 & \\
\hline 2009.10.02 & SPOT 5 Bands 1-4 & - & \\
\hline
\end{tabular}

Majiliang and Ya'erya, in which Fengzijian is the most serious region in coal spontaneous combustion of Shanxi.

\subsection{Data sources and preprocessing}

In comparison with traditional optical bands, thermal-infrared bands can be better used for detecting coal spontaneous combustion (Mansor et al. 1994; Zhang et al. 2004; Gangopadhyay et al. 2006). Landsat satellite series have been the commonly used data sources for monitoring spontaneous combustion, due to their advantages in temporal, spatial, and spectral resolutions as well as wide swath (Saraf et al. 1995; Mishra et al. 2011; Song et al. 2015). In our study, three-period Landsat-5 TM imagery of 2007, 2009, 2010 and a SPOT-5 high spatial resolution image of 2009 are selected as the primary data sources (table 1).

To perform the dynamic monitoring of using time series remote sensing images, it is highly necessary to carry out the geometric correction. ENVI (Environment for Visualizing Images) is used to finish the accurate geometric registration because of its good compatibility and support for series of Landsat imagery. Specifically, the 2nd order 
polynomial and the nearest neighbour (NN) resampling method are adopted, in which the ground control points (GCPs) such as the obvious points of intersection among roads or rivers, are selected from the Landsat-7 ETM+ orthorectified image. The geometric accuracy is assured to be better than 0.5 pixel. Finally, ENVI and ArcGIS are jointly used for extracting and analyzing the spatial distribution of burnt rocks and the land use classification information. In addition, a 1:50,000 topographic map is also acquired for obtaining the LUCC (e.g., roads, residential areas).

\subsection{Algorithm for retrieving land surface temperature}

LST retrieval from remote sensing imagery can be generally divided into single-channel algorithm, split-window algorithm and multi-channel algorithm, in which single-channel algorithm includes single-window algorithm and universal singlechannel algorithm (Qin et al. 2001; Jiménez-Muñoz and Sobrino 2003). In previous studies, the splitwindow algorithm has been given priority in retrieving LST for detecting temperature-related information using NOAA and MODIS thermal infrared bands (Price 1984; Politi et al. 2012; André et al. 2015). Unfortunately, there is just a thermal infrared band in Landsat-5 TM, so the splitwindow algorithm cannot be used. Here, the singlewindow algorithm is chosen for acquiring the LST (equations 1-5)

$$
\begin{aligned}
T_{s}= & \{a(1-C-D)+[b(1-C-D) \\
& \left.+C+D] T_{b}-D T_{a}\right\} / C
\end{aligned}
$$

where $T_{a}$ is the average atmospheric temperature, $T_{b}$ is the brightness temperature $(\mathrm{K})$ of a pixel in the Landsat-5 TM thermal infrared band, and $C$ and $D$ can be obtained by the following formula

$$
\begin{aligned}
& C=\tau \varepsilon \\
& D=(1-\tau)[1+\tau(1-\varepsilon)]
\end{aligned}
$$

where $\varepsilon$ is the land surface emissivity, and $\tau$ is the atmospheric transmittance.

$\varepsilon$ is one of the key parameters for retrieving the LST. At present, the normalized difference vegetation index (NDVI) is used to obtain the parameter (equations 4 and 5). In addition, $\tau$ is also a key parameter which mainly depends on the dynamic changes in atmospheric moisture content (Srivastava et al. 2014).

$$
\begin{aligned}
\varepsilon & =1.0094+0.047 \operatorname{Ln}(\mathrm{NDVI}) \\
\mathrm{NDVI} & =\left(\rho_{\mathrm{NIR}}-\rho_{\text {Red }}\right) /\left(\rho_{\mathrm{NIR}}+\rho_{\text {Red }}\right)
\end{aligned}
$$

where $\rho_{\text {NIR }}$ and $\rho_{\text {Red }}$ represent the LST of nearinfrared (NIR) band and red band, respectively.

\subsection{Spatial overlay analysis}

After coal seam burns, its overlying strata will be changed to brick red and gray-white burnt rock due to the heat. Meanwhile, some secondary disasters (e.g., surface subsidence, ground fissure) will also occur. The distribution of burnt rocks information can be added into the LST based thermal anomalies for accurately locating coal-seam spontaneous combustion areas. At the same time, residential areas and roads should be removed, because they are artificial thermal anomalies.

Burnt rocks and residential areas are extracted by a decision-tree classification method based on a high spatial resolution SPOT-5 image. Then, the regions of burnt rocks and thermal anomaly areas are interactively overlaid to keep the same regions. Residential areas and roads are eliminated to obtain high-suspected spontaneous combustion areas. The identification accuracy of coalseam spontaneous combustion can be effectively improved by modifying thermal anomaly areas. Most of the processing procedures are automatically carried out by a supervised classification method in ENVI, and the result is exported to ArcMap to perform the spatial overlay analysis. Finally, in-situ validation is also required to check the suspected regions by measuring the LST, finding the gas from ground fissure and visiting local people.

\subsection{A multiple-factor analysis method}

Identification of the coal spontaneous combustion is generally affected by multiple disturbance factors such as forest fires, geothermal energy, and thermal power stations. First, those thermal anomaly areas must be excluded from the potential coal spontaneous combustion. An exclusion method is used to exclude the other thermal anomaly areas than coal spontaneous combustion. For example, in our study, three factors are considered to obtain accurate spontaneous combustion areas, including LST derived from Landsat TM, burnt rocks 


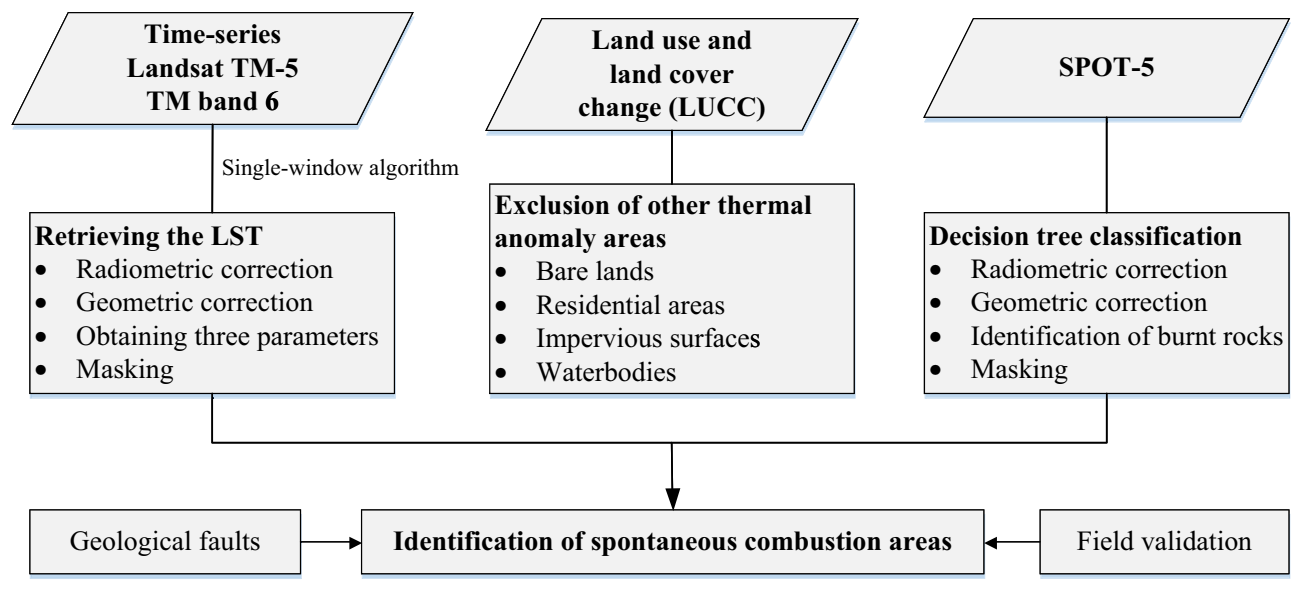

Figure 2. General workflow for identifying potential coal spontaneous combustion.

derived from SPOT-5 and spatial distribution of LUCC from the 1:50,000 topographic map (figure 2). The new methodology developed in this study is achieved following four primary steps, including selection of remote sensing data sources (optical and thermal infrared imagery), data preprocessing procedures, identification of thermal anomalies of underground coal fire, and spatial overlay analysis. Firstly, several key maps are spatially overlaid including land use map, coalfield distribution map, burnt rock distribution map and thermal anomaly distribution map of spontaneous combustion of coal seam. The colliery distribution map is used to identify the specific thermal anomalies within the scope of coalfield distribution map. Land use map is then used to exclude the hot islands caused by human aggregation areas. The rest thermal anomaly areas are intersected with the burnt rock distribution map for acquiring the thermal anomaly areas of spontaneous combustion of coal seam.

\subsection{Dynamic analysis of coal spontaneous combustion}

Dynamic degree is used to measure the dynamic change rate of coal fire areas, which can show how a coal fire changes over time within the study area (Liu et al. 2003)

$$
L=\frac{U_{b}-U_{a}}{U_{a}} \times 100 \%
$$

where $L$ is the dynamic degree of spontaneous combustion of coal within the analysis period; $U_{a}$ and $U_{b}$ are respectively the early and late area of coal spontaneous combustion.

\section{Results}

\subsection{Analysis of time series LSTs}

Three spatial distribution maps of LSTs are acquired in the coal spontaneous combustion areas (figure 3). The Landsat TM derived LST of the anomalous areas have been subsequently validated by the field observations. The ground truth data are collected between typical coal fire areas and other thermal anomalies by a hand-held infrared thermometer, which are used to distinguish thermal anomalies from non-coal fire areas. To locate the surface anomalous zones of coalfield, spatial analysis is carried out on the surface thermal anomaly areas by overlaying basic geographic information data, distribution maps of burning rocks and land use maps. Four known coal fire zones of Majiliang, Kushu village, Yaerya and Malinjian cliffs are used as the prior data, and a total of 10 suspected coal-seam spontaneous combustion areas are obtained after a comprehensive analysis. It can be seen that the maximum temperature $\left(T_{\max }\right)$ is $38.6^{\circ} \mathrm{C}$, the minimum temperature $\left(T_{\min }\right)$ is $13.9^{\circ} \mathrm{C}$, and the average temperature $\left(T_{\text {ave }}\right)$ is $26.3^{\circ} \mathrm{C}$ on September 15, 2007; they are $40.1,15.5$, $27.8^{\circ} \mathrm{C}$, respectively, on September 20, 2009; and $35.5,10.8,23.15^{\circ} \mathrm{C}$, respectively, on July 5, 2010. The maximum difference of $T_{\max }$ is $4.6^{\circ} \mathrm{C}$, while it is $4.7^{\circ} \mathrm{C}$ of $T_{\min }$.

In addition, the time series LSTs of Majiliang and Kushu village fire areas are shown in figure 4. The change information of underground coal fires can be observed during the four years. It is obvious that the thermal anomalies have been showing the higher temperature than other places. The average temperature stays above $300 \mathrm{~K}$. 

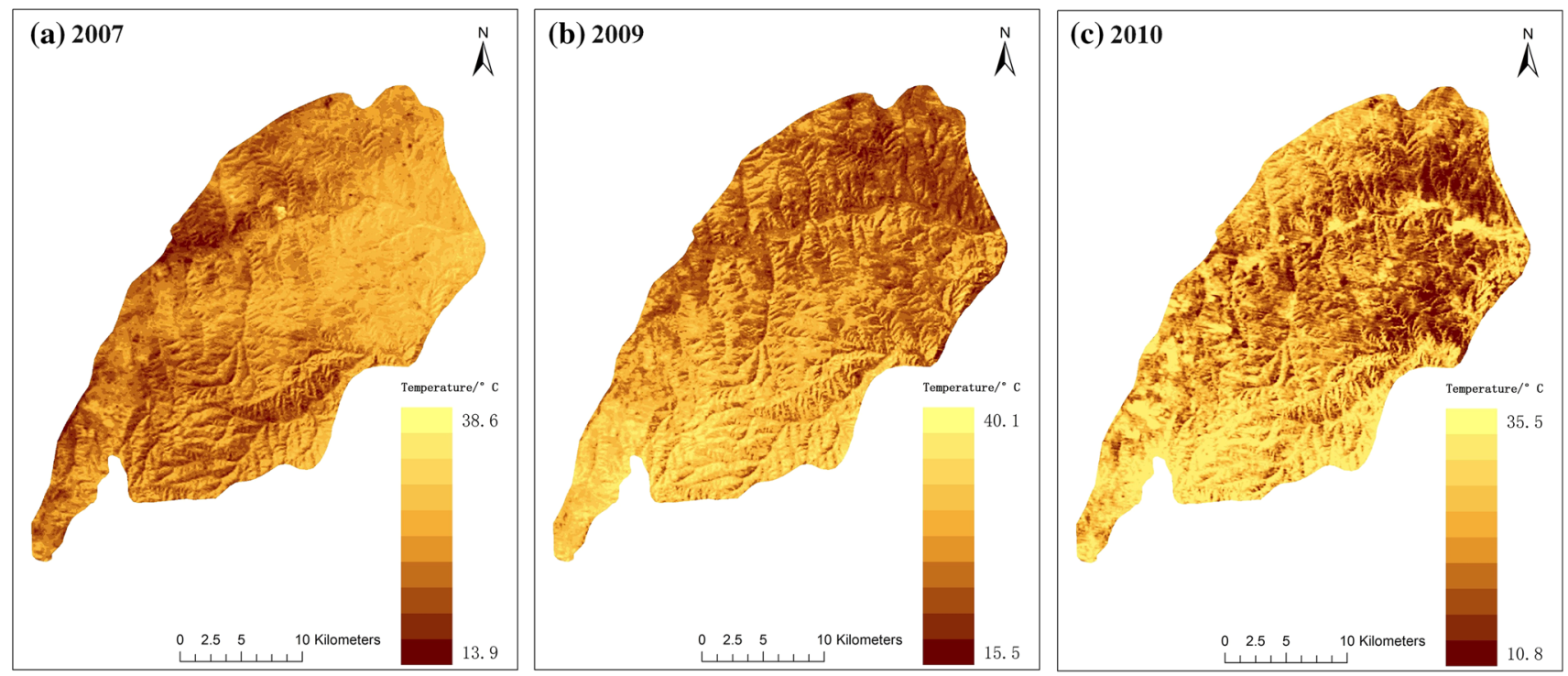

Figure 3. Spatial distribution and dynamic changes of three-period LSTs in the study area.
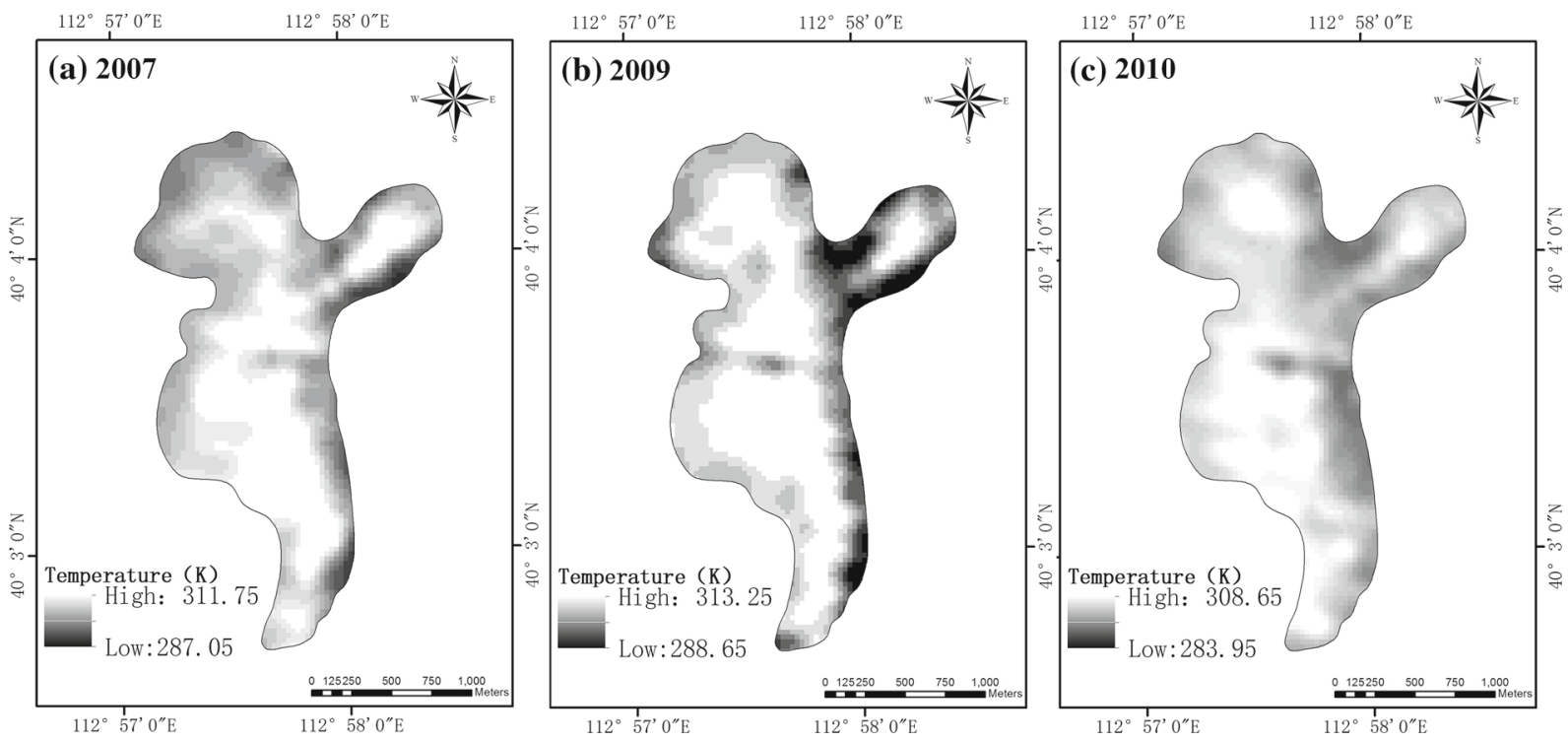

Figure 4. Retrieved LSTs of the in the Majiliang and Kushu village.

\subsection{Identification and validation of coal fire areas}

After analyzing the temperature of known coal fire areas, the threshold values were located between 35 and $40^{\circ} \mathrm{C}$ for potential target zones. It is highly necessary to perform the field investigation procedures. All of the suspected coal fire areas were investigated by the in-situ visual inspection in December 2011. The coordinates were firstly input into a sub-meter handheld GPS and they were positioned in the field survey. To assist the exclusion of non-coal fire areas, high-resolution SPOT-5 imagery is used to identify the spatial distribution of burnt rocks by a decision-tree classification algorithm (figure 5). The land use map was used to exclude the other thermal anomalies out of the coalfield. In addition, the ground truth data are also collected between typical coal fire areas and other thermal anomalies by a hand-held infrared thermometer and a sub-meter handheld GPS, which are used to distinguish thermal anomalies from non-coal fire areas.

The ground truth data were collected between typical coal fire areas and other thermal anomalies by a hand-held infrared thermometer, which are used to distinguish thermal anomalies from noncoal fire areas. For example, some photographs of typical coal fire areas were also taken as the reference data (figure 6). A total of 10 coal fire areas were identified based on our proposed method, 


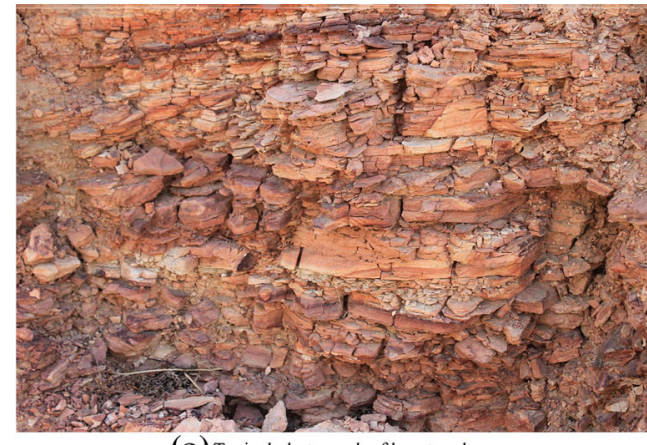

(a) Typical photograph of burnt rocks

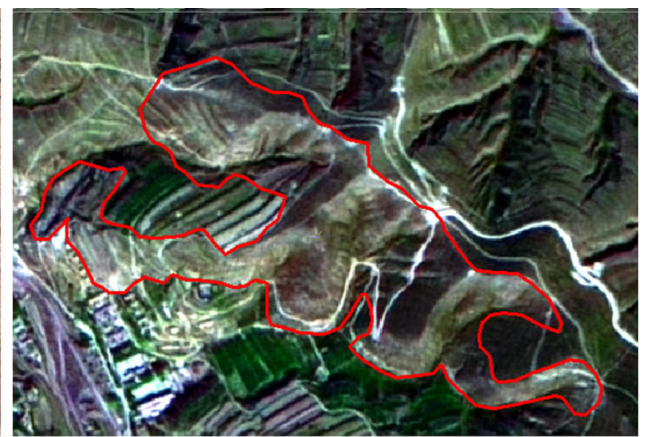

(b) Spatial distribution of the identified burnt rocks using SPOT-5 imagery

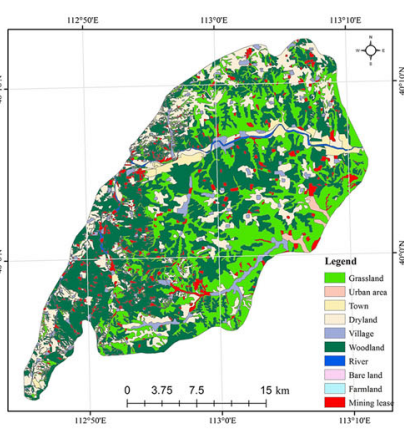

(c) Land use map of the study area

Figure 5. Identified distribution areas (b) of burnt rocks and land use map (c).
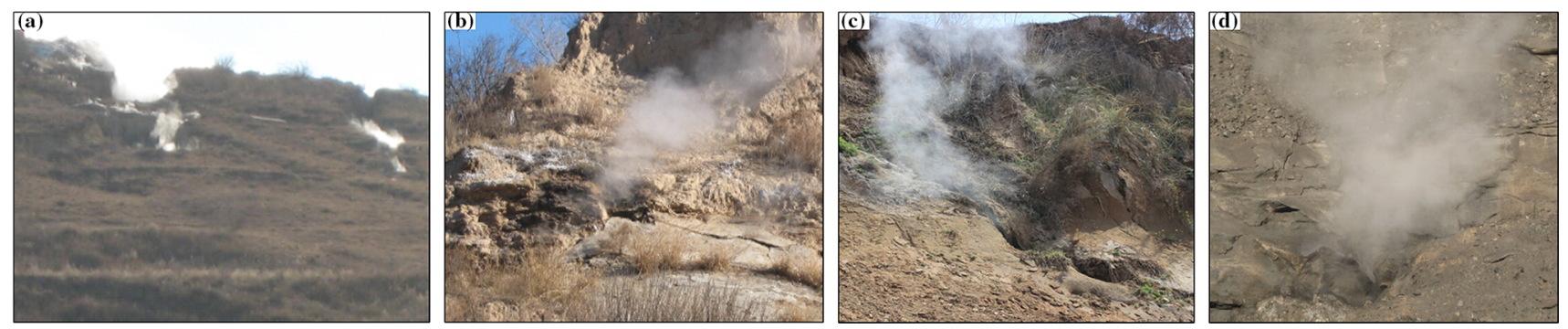

Figure 6. Photographs for the in-situ validation in the coal-fire areas. (a) Kushu village, (b) Malin Jian, (c) Guanyao village, and (d) Huangtu Po.

Table 2. Area and percentage statistics of identified coal fire areas in the study area during 2007-2010.

\begin{tabular}{|c|c|c|c|c|c|c|}
\hline & \multicolumn{2}{|c|}{2007} & \multicolumn{2}{|c|}{2009} & \multicolumn{2}{|c|}{2010} \\
\hline & $\begin{array}{c}\text { Area } \\
\left(10,000 \mathrm{~m}^{2}\right)\end{array}$ & $\begin{array}{c}\text { Percentage } \\
(\%)\end{array}$ & $\begin{array}{c}\text { Area } \\
\left(10,000 \mathrm{~m}^{2}\right)\end{array}$ & $\begin{array}{c}\text { Percentage } \\
(\%)\end{array}$ & $\begin{array}{c}\text { Area } \\
\left(10,000 \mathrm{~m}^{2}\right)\end{array}$ & $\begin{array}{c}\text { Percentage } \\
(\%)\end{array}$ \\
\hline Coal fire areas & 683.860 & 1.08 & 702.270 & 1.11 & 761.057 & 1.20 \\
\hline
\end{tabular}

but two additional ones were found in the in-situ validation. The total extraction accuracy was $83.33 \%$.

\subsection{Changes of spontaneous combustion areas}

In comparison with the monitoring of spontaneous combustion areas for a year, it is more important to find the dynamic changes of the spontaneous combustion during a certain time interval. A total of 12 coal fire areas have been found during 2007-2010 after revising the original interpretation results (table 2). The coal fire areas have accounted for more than 1\% during 2007-2010. Specifically, an increase of $184,100 \mathrm{~m}^{2}$ has been caused and they increased by $0.03 \%$ from 2007 to 2009; there is an increase of $587,870 \mathrm{~m}^{2}$ and $0.09 \%$ from 2009 to 2010. Similarly, the increased area is $771,970 \mathrm{~m}^{2}$ during 2007-2010 with an increased percentage of $0.12 \%$. There is an average annual increase of $257,320 \mathrm{~m}^{2}$ and $3.78 \%$ of coal spontaneous combustion, and the dynamic degree is $11.29 \%$ from 2007 to 2010. It is obvious that there is a continuous increase of coal fire areas from 2007 to 2010. Three dynamic change maps of coal fire areas during 2007-2009, 2009-2010 and 2007-2010 are formed by spatial overlay display (figure 7). At the same time, the area changes and change rates of 12 coal spontaneous combustion areas are also obtained (table 3 ).

\section{Discussion}

\subsection{Land surface temperature retrieval of coal fire areas}

There are some differences among the three-period LSTs due to different seasons, acquisition time of remote sensing imagery, different land cover 

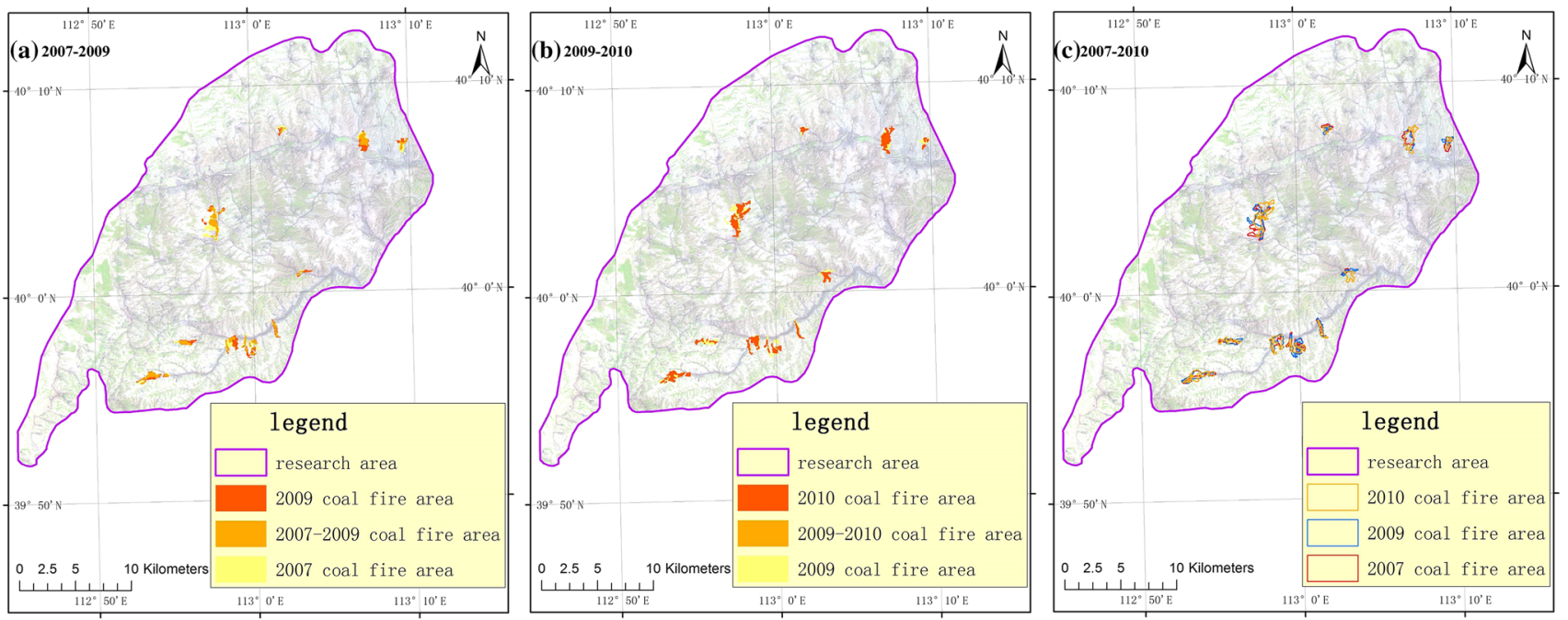

Figure 7. Dynamic changes of coal spontaneous combustion in the study area.

types, different climate conditions, different conditions of underground coal fire spontaneous combustion, and different land surface thermal radiation, etc. It is highly necessary to exclude the disturbance factors for LST retrieval, especially for the remote sensing based LST retrieval in the coal fire areas (Prashanthi and Kulkarni 2005). Alternately, the potential coal fire areas can be firstly identified by removing other land cover types, and then the real underground coal spontaneous combustion can be assured by referring to the sample points.

In addition, the spatial resolution of thermal infrared image is an important factor for affecting the identification accuracy of coal spontaneous combustion (Wan et al. 2004; Inamdar et al. 2008). In our study, $120 \mathrm{~m}$ Landsat-5 TM thermal infrared band is used and those areas less than a pixel $(120 \times 120 \mathrm{~m})$ cannot be extracted. Additionally, some of burnt rocks are omitted due to the changes of seasonal land surface coverage. Higher resolution thermal infrared imagery should be used for the identification of burning rocks, especially using the imagery of winter. At the same time, a variety of causing factors should be paid attention, which greatly affect the LST accuracy, e.g., the imaging season of Landsat TM remote sensing imagery, land features, meteorological conditions, underground coal fires, land surface thermal radioactive situations. It is impossible to consider all the affecting factors. In our study, the thermal anomaly caused by spontaneous combustion of coal seam is mainly considered. The joint analysis method is used to achieve the goal. The coalfield distribution map is used to exclude the thermal anomalies of non-coal fire areas. Land use map is used to exclude the other thermal anomalies. Finally, the intersection is performed to acquire the accurate coal fires by spatial overlay analysis.

\subsection{Dynamic changes of spontaneous combustion}

To validate the identification of spontaneous combustion of coal seam, Yanya and Wajinwan, the ancient fire areas, are located in the upstream of Kouquan ditch, which are famous as the 'red strata' (burnt rocks) distribution areas. The ground truth data are collected between typical coal fire areas and other thermal anomalies by a hand-held infrared thermometer, which are used to distinguish thermal anomalies from non-coal fire areas. In our study, coal fire areas are still distributed densely in this area on the maps of 2007, 2009 and 2010. The reason may be that the ancient fire areas, live fire zones, are still burning, which has been proved in the in-situ validation. When the coal fire areas are extracted, burning rocks can be used as an important auxiliary data. Nevertheless, attention should be paid that not all burnt rocks are necessarily live fire zones. Tow conditions, thermal anomaly areas and burnt rocks, should be the intersection rather than the union. More attention should be paid to improve the accuracy of land surface temperature retrieval and identification of burnt rocks.

The changes of coal fire areas are relatively small, and there is only $0.03 \%$ during 2007-2009 over a 2-year time span. Conversely, they are larger and there is an increase of $0.09 \%$ from 2009 to 2010. One of the reasons is that there is a merging 
Table 3. Area change and change rates of twelve focal coal spontaneous combustion areas from 2007 to 2010

\begin{tabular}{|c|c|c|c|c|}
\hline No. & $\begin{array}{c}\text { Temporal } \\
\text { interval }\end{array}$ & $\begin{array}{l}\text { Area change } \\
\left(10,000 \mathrm{~m}^{2}\right)\end{array}$ & $\begin{array}{l}\text { Change rate } \\
(\%)\end{array}$ & Analysis of change features \\
\hline \multirow[t]{2}{*}{1} & 2007-2009 & 10.8108 & 0.36 & $\begin{array}{l}\text { The spatial distribution of coal fire areas is } \\
\text { relatively fixed along with a slight increase }\end{array}$ \\
\hline & 2009-2010 & -8.5885 & -0.21 & $\begin{array}{l}\text { The spatial distribution of coal fire areas is } \\
\text { relatively fixed along with a slight decrease }\end{array}$ \\
\hline \multirow[t]{2}{*}{2} & 2007-2009 & 12.5083 & 0.14 & $\begin{array}{l}\text { The spatial distribution of coal fire areas is } \\
\text { relatively fixed along with a slight increase }\end{array}$ \\
\hline & 2009-2010 & 9.9819 & 0.10 & $\begin{array}{l}\text { There is fragmentation trend of the distribution of } \\
\text { coal fire areas }\end{array}$ \\
\hline \multirow[t]{2}{*}{3} & 2007-2009 & 11.062 & 0.84 & $\begin{array}{l}\text { There is a general rapid expansion to the east } \\
\text { with an increase of coal fire areas }\end{array}$ \\
\hline & 2009-2010 & 24.3972 & 1.01 & $\begin{array}{l}\text { There is a general movement to the south with an } \\
\text { increase of the total area }\end{array}$ \\
\hline \multirow[t]{2}{*}{4} & 2007-2009 & 7.6932 & 1.02 & $\begin{array}{l}\text { The range of coal fire areas is increased year by } \\
\text { year }\end{array}$ \\
\hline & 2009-2010 & 23.099 & 1.52 & $\begin{array}{l}\text { The range of coal fire areas is gradually merged } \\
\text { with Majiliang fire areas }\end{array}$ \\
\hline \multirow[t]{2}{*}{5} & $2007-2009$ & -71.2114 & -0.37 & Fire area scope reduced year by year \\
\hline & 2009-2010 & 30.3655 & 0.25 & $\begin{array}{l}\text { Fire area scope aggregated with Kushu village fire } \\
\text { are yearly }\end{array}$ \\
\hline \multirow[t]{2}{*}{6} & $2007-2009$ & 24.7597 & 0.29 & $\begin{array}{l}\text { The overall scope of fire area increased year by } \\
\text { year }\end{array}$ \\
\hline & 2009-2010 & 25.332 & 0.23 & $\begin{array}{l}\text { There is a general rapid expansion to the north } \\
\text { and the south with an increase of coal fire areas }\end{array}$ \\
\hline \multirow[t]{2}{*}{7} & $2007-2009$ & -2.2749 & -0.05 & The range of coal fire areas is reduced year by year \\
\hline & $2009-2010$ & -17.57 & -0.40 & $\begin{array}{l}\text { There is generally a decentralized trend with a } \\
\text { decrease of coal fire areas }\end{array}$ \\
\hline \multirow[t]{2}{*}{8} & $2007-2009$ & -6.93 & -0.26 & $\begin{array}{l}\text { The overall scope of fire area was expansion to the } \\
\text { west, with area reduced }\end{array}$ \\
\hline & 2009-2010 & 5.2883 & 0.27 & $\begin{array}{l}\text { The range of coal fire areas is gradually merged } \\
\text { with an increase of fire area }\end{array}$ \\
\hline \multirow[t]{2}{*}{9} & $2007-2009$ & -9.9014 & -0.18 & $\begin{array}{l}\text { The range of coal fire areas is gradually merged } \\
\text { with a slight decrease }\end{array}$ \\
\hline & 2009-2010 & -1.0556 & -0.02 & $\begin{array}{l}\text { The range of coal fire areas is gradually merged } \\
\text { with a slight decrease }\end{array}$ \\
\hline \multirow[t]{2}{*}{10} & $2007-2009$ & 6.2459 & 0.19 & $\begin{array}{l}\text { The range of coal fire areas is gradually merged } \\
\text { with Shuangjinggou fire areas }\end{array}$ \\
\hline & $2009-2010$ & -19.5861 & -0.49 & The range of coal fire areas is reduced year by year \\
\hline \multirow[t]{2}{*}{11} & 2007-2009 & 15.3803 & 0.38 & $\begin{array}{l}\text { The range of coal fire areas is increased year by } \\
\text { year }\end{array}$ \\
\hline & 2009-2010 & -18.4794 & -0.33 & $\begin{array}{l}\text { There is generally a decentralized trend with a } \\
\text { decrease of coal fire areas }\end{array}$ \\
\hline \multirow[t]{2}{*}{12} & $2007-2009$ & 20.2683 & 0.32 & $\begin{array}{l}\text { There is a general rapid expansion to the east } \\
\text { with an increase of coal fire areas }\end{array}$ \\
\hline & 2009-2010 & 5.6019 & 0.07 & There is a decentralized trend of coal fire areas \\
\hline
\end{tabular}

trend from 2009 to 2010. Original small spots are aggregated into larger spots and the gap zones between small spots are also included, which results in a rapid increase of coal fire areas. In addition, most of coal fire areas exist independently in the study area, but several areas had a connecting trend due to a relatively close distance (figure 6). As shown in table 3, there is a sustainable increase of nos. 2, 3, 4, 6 and 12, in which there is the largest growth rate of no. 4 and it reaches by $2.54 \%$ during the study period. The reason may be that effective measurements are not adopted and the continuous 
development of coal-seam spontaneous combustion are resulted in. Conversely, there is a sustainable decrease for nos. 7 and 9. There is a decentralized trend for no. 7, while there is a gradual merging trend for no. 9. The reason may be that a large number of mined-out areas, which result in insufficient burning materials for sustainable spontaneous combustion. Geophysical detecting methods can be jointly used to accurately find out the spontaneous combustion center and the spatial range for preventing underground coal-seam spontaneous combustion.

\section{Conclusion}

Datong Jurassic coal mining area, China, a typical live fire zone, is used as the study area. The LST retrieval is firstly carried out using a single-window algorithm based on the time series Landsat-5 TM thermal infrared bands during 2007-2010. Coalseam spontaneous combustion is then identified and dynamically analyzed by a joint method of an exclusion method and a multiple-factor analysis method, including LST, spatial distribution of burnt rocks, roads, and other artificial thermal anomaly areas. The proposed method in our study is proved to be effective and convenient for quickly acquiring spontaneous combustion, especially for the dynamic monitoring and assessment based on Landsat series. However, the accuracy of LST retrieval can have a great impact on the identification of spontaneous combustion. In addition to the improvement of LST retrieval algorithms based on single-band Landsat TM-5, the remotely sensed imagery with higher spatial resolution and more thermal infrared bands can be used as the new data sources.

\section{Acknowledgement}

This work was financially supported by National Key Research and Development Program of China (2016YFD0800904).

\section{References}

André C, Ottlé C, Royer A and Maignan F 2015 Land surface temperature retrieval over circumpolar Arctic using SSM/I-SSMIS and MODIS data; Remote Sens. Environ. $1621-10$.
Gangopadhyay P K, Lahiri-Dutt K and Saha K 2006 Application of remote sensing to identify coal fires in the Raniganj Coal belt, India; Int. J. Appl. Earth Obs. 8(3) 188-195.

Hochstein M P and Dickinson D J 1970 Infra-red remote sensing of thermal ground in the Taupo region, New Zealand; Geothermics 2 420-423.

Hu X, Yang S, Zhou X, Yu Z and Hu C 2015 Coal spontaneous combustion prediction in gob using chaos analysis on gas indicators from upper tunnel; J. Nat. Gas Sci. Eng. 26 461-469.

$\mathrm{Hu} \mathrm{Z}$ and Xia Q 2017 An integrated methodology for monitoring spontaneous combustion of coal waste dumps based on surface temperature detection; Appl. Therm. Eng. 122 $27-38$.

Inamdar A K, French A, Hook S, Vaughan G and Luckett W 2008 Land surface temperature retrieval at high spatial and temporal resolutions over the southwestern United States; J. Geophys. Res. 113(D7) D07107.

Jiang W, Jia K, Chen Z, Deng Y and Rao P 2017 Using spatiotemporal remote sensing data to assess the status and effectiveness of the underground coal fire suppression efforts during 2000-2015 in Wuda, China; J. Clean. Prod. $142565-577$.

Jiménez-Muñoz J C and Sobrino J A 2003 A generalized single-channel method for retrieving land surface temperature from remote sensing data; J. Geophys. Res. 108(D22) 4688-4696.

Liu J, Liu M, Zhuang D, Zhang Z and Deng X 2003 Study on spatial pattern of land-use change in China during 19952000; Sci. China Ser. D 46(4) 373-384.

Lu Y and Qin B 2015 Identification and control of spontaneous combustion of coal pillars: A case study in the Qianyingzi Mine, China; Nat. Hazards 75(3) 2683-2697.

Mansor S B, Cracknell A P, Shilin B V and Gornyi V I 1994 Monitoring of underground coal fires using thermal infrared data; Int. J. Remote Sens. 15(8) $1675-1685$.

Mishra R K, Bahuguna P P and Singh V K 2011 Detection of coal mine fire in Jharia Coal Field using Landsat-7 ETM+ data; Int. J. Coal Geol. 86(1) 73-78.

Nelson M I and Chen X D 2007 Survey of experimental work on the self-heating and spontaneous combustion of coal; Rev. Eng. Geol. 18 31-83.

Oppenheimer D H 1986 Extensional tectonics at the Geysers geothermal area, California; J. Geophys. Res. 91(B11) 11463-11476.

Pal S K, Vaish J, Kumar S and Bharti A K 2016 Coal fire mapping of East Basuria Colliery, Jharia coalfield using vertical derivative technique of magnetic data; J. Earth Syst. Sci. 125(1) 165-178.

Politi E, Cutler M E and Rowan J S 2012 Using the NOAA advanced very high resolution radiometer to characterize temporal and spatial trends in water temperature of large European lakes; Remote Sens. Environ. 126 1-11.

Prashanthi S K and Kulkarni S 2005 Coal-fire detection and monitoring in Raniganj coalfield, India - A remote sensing approach; Curr. Sci. 88(1) 21.

Price J C 1984 Land surface temperature measurements from the split window channels of the NOAA 7 Advanced Very High Resolution Radiometer; J. Geophys. Res. 89(D5) 7231-7237. 
Qin Z, Karnieli A and Berliner P 2001 A mono-window algorithm for retrieving land surface temperature from Landsat TM data and its application to the IsraelEgypt border region; Int. J. Remote Sens. 22(18) 3719-3746.

Ren X W, Wang F Z, Guo Q, Zuo Z B and Fang Q S 2015 Application of foam-gel technique to control CO exposure generated during spontaneous combustion of coal in coal mines; J. Occup. Environ. Hyg. 12(11) D239-D245.

Rosema A, Guan H and Veld H 2001 Simulation of spontaneous combustion, to study the causes of coal fires in the Rujigou Basin; Fuel 80(1) 7-16.

Saraf A K, Prakash A, Sengupta S and Gupta R P 1995 Landsat-TM data for estimating ground temperature and depth of subsurface coal fire in the Jharia coal field, India; Int. J. Remote Sens. 16(12) 2111-2124.

Singh A, Raju A, Pati P and Kumar N 2017 Mapping of coal fire in Jharia Coalfield, India: A remote sensing based approach; J. Indian Soc. Remote 45(2) 369-376.

Song Z, Kuenzer C, Zhu H, Zhang Z, Jia Y, Sun Y and Zhang J 2015 Analysis of coal fire dynamics in the Wuda syncline impacted by fire-fighting activities based on insitu observations and Landsat- 8 remote sensing data; Int. J. Coal. Geol. 141 91-102.
Srivastava P K, Han D, Rico-Ramirez M A, Bray M, Islam T, Gupta M and Dai Q 2014 Estimation of land surface temperature from atmospherically corrected LANDSAT TM image using 6S and NCEP global reanalysis product; Environ. Earth Sci. 72(12) 5183-5196.

Stracher G B and Taylor T P 2004 Coal fires burning out of control around the world: Thermodynamic recipe for environmental catastrophe; Int. J. Coal Geol. 59(1) 717.

Wang C, Yang Y, Tsai Y T, Deng J and Shu C M 2016 Spontaneous combustion in six types of coal by using the simultaneous thermal analysis-Fourier transform infrared spectroscopy technique; J. Therm. Anal. Calorim. 126(3) 1591-1602.

Wan Z, Zhang Y, Zhang Q and Li Z L 2004 Quality assessment and validation of the MODIS global land surface temperature; Int. J. Remote Sens. 25(1) 261-274.

Xue S, Dickson B and Wu J 2008 Application of ${ }^{222} \mathrm{Rn}$ technique to locate subsurface coal heatings in Australian coal mines; Int. J. Coal Geol. 74(2) 139-144.

Zhang J, Wagner W, Prakash A, Mehl H and Voigt S 2004 Detecting coal fires using remote sensing techniques; Int. J. Remote Sens. 25(16) 3193-3220. 